\title{
Heterotaxy syndrome with agenesis of dorsal pancreas and diabetes mellitus: case report and review of the literature
}

Cínthia Minatel Riguetto', Samantha Pelichek' ${ }^{\prime}$ Arnaldo Moura Neto'

\begin{abstract}
SUMMARY
Heterotaxy syndrome (HS) is a rare congenital condition with multifactorial heritance, characterized by an abnormal arrangement of thoraco-abdominal organs and vessels. Patients present with multiple cardiac, gastrointestinal, hepatosplenic, pancreatic, renal, neurological and skeletal disorders without any pathognomonic alteration. Despite the described increased risk of diabetes mellitus (DM) in patients with altered pancreatic anatomy, just one case was reported in Korea regarding the association of HS and DM in a 13-year-old girl. Our report refers to a 40-year-old female Brazilian patient with a history of DM and HS with polysplenia and agenesis of dorsal pancreas without cardiac abnormalities. She presented a worsening glycemic control associated with weight gain and signs of insulin resistance. After a proper clinical management of insulin and oral medications, our patient developed an improvement in glycemic control. Although it is a rare disease, HS with polysplenia and pancreatic disorders can be associated with an increased risk of DM. This case highlights the importance of investigating DM in patients with HS, especially those with pancreatic anatomical disorders, for proper clinical management of this rare condition. Arch Endocrinol Metab. 2019;63(4):445-8
\end{abstract}

1 Divisão de Endocrinologia, Faculdade de Ciências Médicas, Universidade de Campinas, Campinas, SP, Brasil

Correspondence to: Cinthia Minatel Riguetto Faculdade de Ciências Médicas, Universidade de Campinas Rua Tessália Vieira de Camargo, 126 13084-971 - Campinas, SP, Brasil cinthia.mr@hotmail.com

Received on Dec/28/2018 Accepted on Apr/5/2019

DOI: $10.20945 / 2359-3997000000142$

\section{INTRODUCTION}

$\mathrm{H}$ eterotaxy syndrome (HS) is a rare congenital condition with multifactorial inheritance characterized by an abnormal arrangement of thoracoabdominal organs and vessels. Patients present with multiple cardiac, gastrointestinal, hepatosplenic, pancreatic, renal, neurological and skeletal disorders without any pathognomonic alteration (1-3). The first case was described in 1929 and the disease has an incidence rate of 1 in 15,000 live births. HS has two main classifications: HS with polysplenia, which presents with thoraco-abdominal abnormalities and multiple spleens; and HS with asplenia $(4,5)$. Patients with polysplenia eventually have short pancreas or agenesis of the dorsal pancreas, a feature related to an increased risk of pancreatitis and diabetes mellitus - DM $(6,7)$. Despite the described increased risk of DM, we found just one case report associated with DM in a 13-yearold girl with HS and pancreatic disorder (8). We report a case of a 40-year-old female patient with HS and polysplenia in association with DM due to agenesis of dorsal pancreas.

\section{CASE REPORT}

A 40-year-old non-Caucasian female Brazilian patient presented to the Endocrinology Division of the University Hospital at Campinas in June 2017, complaining of fatigue, polyphagia, polyuria, polydipsia and weight loss $(5 \mathrm{~kg})$ for 30 days.

The patient had been diagnosed with DM, hypertension, dyslipidemia and HS four years earlier and was currently using metformin $2 \mathrm{~g}$ /day, gliclazide $90 \mathrm{mg}$ /day, enalapril $20 \mathrm{mg} /$ day, hydrochlorothiazide $25 \mathrm{mg} /$ day and simvastatin $20 \mathrm{mg} /$ day. She worked as a secretary for about 60 hours a week, did not do exercises and had a high carbohydrate intake diet, especially with industrialized products. She did not have any family history of DM or other relevant diseases. Information retrieved from her medical history showed good glycemic control and body weight until July 2016, when the patient presented a glycosylated hemoglobin (HbAlc) of 6.6\%, fasting plasma glucose (FPG) of 143 $\mathrm{mg} / \mathrm{dL}$, weight of $66 \mathrm{~kg}$ and body mass index (BMI) of $22.83 \mathrm{~kg} / \mathrm{m}^{2}$. However, in March 2017, those 
parameters increased, and she presented an $\mathrm{HbAlc}$ of $8.3 \%$, FPG of $174 \mathrm{mg} / \mathrm{dL}$, weight of $76 \mathrm{~kg}$ and BMI of $26.29 \mathrm{~kg} / \mathrm{m}^{2}$.

In further investigation from medical records, an abdominal magnetic resonance imaging (MRI) and a cholangiopancreatography MRI from March 2016 showed agenesis of dorsal pancreas with increased dimensions of the pancreas head (Figure 1). The liver was enlarged and presented an ectopic location, situated in a central position in the abdomen. Also, there were signs of non-homogenous steatosis. Intestinal malrotation was also seen, with the stomach and angle of Treitz located to the right, with a predominance of small intestines in the right hemiabdomen. The spleen was dislocated from the usual position. In the right hypochondrium, there were multiple nodular images with lobulated contours, similar to splenic parenchyma. No renal, gallbladder or aortic disorders were found. An echocardiogram did not show any alterations in cardiac position or function.

On clinical examination, the patient presented with a weight of $71 \mathrm{~kg}$, height of $1.70 \mathrm{~m}$, BMI of 24.56 $\mathrm{kg} / \mathrm{m}^{2}$, blood pressure of $120 / 80 \mathrm{mmHg}, 89$ heart beats/minute and waist circumference of $98 \mathrm{~cm}$. Acanthosis nigricans was noted in the cervical, axillary and inguinal regions. No alteration was found during the pulmonary and cardiologic exam. Upon abdominal examination, a parenchymal consistency mass was palpated in the mesogastric region.

Blood tests showed an HbAlc of 10.2\%, FPG 142 $\mathrm{mg} / \mathrm{dL}, \mathrm{C}$-peptide $0.91 \mathrm{ng} / \mathrm{mL}$ (normal range 0.8 $4.2 \mathrm{ng} / \mathrm{mL})$, microalbuminuruia $60.9 \mathrm{mg} / \mathrm{L}$, aspartate aminotransferase (AST) $37 \mathrm{U} / \mathrm{L}$ (normal range <

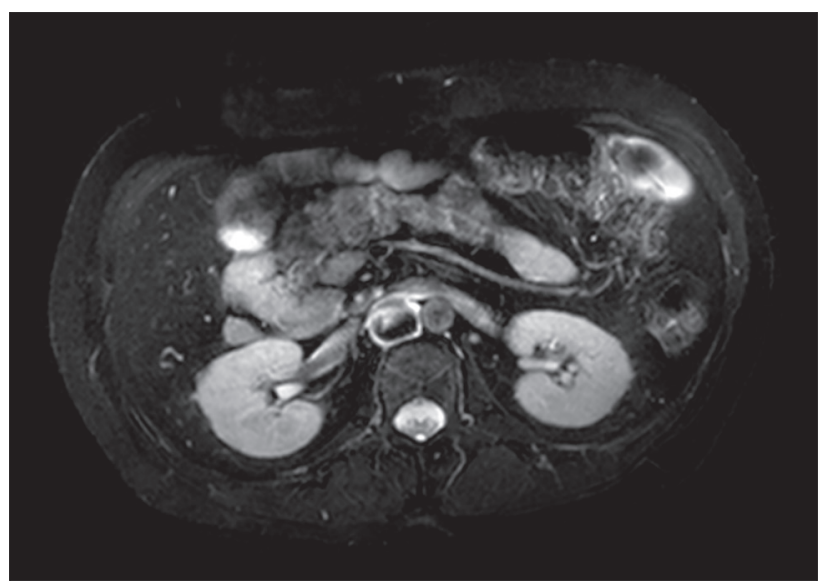

Figure 1. Abdominal MRI and cholangiopancreatography MRI showing agenesis of dorsal pancreas with increased dimensions of the pancreas head.
$35 \mathrm{U} / \mathrm{L}$ ), alanine aminotransferase (ALT) $65 \mathrm{U} / \mathrm{L}$ (normal range $<35 \mathrm{U} / \mathrm{L}$ ), alkaline phosphatase (ALP) $137 \mathrm{U} / \mathrm{L}$ (normal range 30-120 U/L) and gammaglutamyl transferase (GGT) $730 \mathrm{U} / \mathrm{L}$ (normal range 9-64 U/L). The tittles of autoantibodies (islet cell antibody, anti-glutamine acid decarboxylase antibody and anti-insulin antibody) were negative.

Oral medications were discontinued, and $\mathrm{NPH}$ and regular insulin were started and progressively increased. The patient achieved a total dose of 120 IU per day to obtain good glycemic control associated with nutritional education and less industrialized carbohydrate intake. After 30 days of well-controlled blood glucose levels, metformin 1.5 grams/day was reintroduced and sitagliptin $100 \mathrm{mg} /$ day added to the regimen, since the patient had evident signs of insulin resistance, such as acanthosis nigricans and increased abdominal circumference. Two months after the reintroduction of oral medications, the total insulin dose had been reduced to 30 IU per day.

Three months after the first appointment, the patient reported an improvement in asthenia, tiredness, and quality of life, mainly because she was sleeping better since the polyuria stopped. On clinical examination, she presented with a weight of $77 \mathrm{~kg}$, waist circumference of $102 \mathrm{~cm}$, BMI $26.64 \mathrm{~kg} / \mathrm{m}^{2}$ and her $\mathrm{HbAlc}$ decreased to $6.8 \%$. Other laboratorial parameters were also improved: FPG $145 \mathrm{mg} / \mathrm{dL}$, C-peptide $2.45 \mathrm{ng} / \mathrm{mL}$, AST $25 \mathrm{U} / \mathrm{L}$, ALT $41 \mathrm{U} / \mathrm{L}$, ALP 131 $\mathrm{U} / \mathrm{L}$ and GGT $429 \mathrm{U} / \mathrm{L}$. Evolution of clinical and laboratorial parameters are described in Table 1 . The patient maintains regular clinical follow-ups with an endocrinologist, nutritionist, and gastroenterologist to control all the abnormalities associated with the syndrome.

The significant challenges, in this case, are mainly related to the rarity of $\mathrm{HS}$ and the difficulty of establishing whether it could be a case of DM type 2 in a patient with reduced pancreas or if diabetes was only secondary to pancreas agenesis.

\section{DISCUSSION}

HS is an anomaly due to a defect of lateralization during the early embryonic process, with an approximated incidence rate of 1 in 15,000 live births. It is more prevalent in men, at a ratio of $2: 1(4,9,10)$. This inability of lateralization is most often sporadic, but genetic inheritance has been proposed, such as 
Table 1. Clinical and laboratory parameters before the first evaluation and in subsequent visits

\begin{tabular}{|c|c|c|c|c|}
\hline $\begin{array}{l}\text { Clinical and Laboratory } \\
\text { Parameters }\end{array}$ & $\begin{array}{l}\text { July } \\
2016\end{array}$ & $\begin{array}{l}\text { March } \\
2017\end{array}$ & $\begin{array}{l}\text { June } \\
2017\end{array}$ & $\begin{array}{l}\text { October } \\
2017\end{array}$ \\
\hline Weight (kg) & 66 & 76 & 71 & 77 \\
\hline Body Mass Index (kg/m²) & 22.83 & 26.29 & 24.56 & 26.64 \\
\hline Waist circumference (cm) & & & 94 & 102 \\
\hline $\begin{array}{l}\text { Fast plasma glucose } \\
\text { (RV 65-99 mg/dL) }\end{array}$ & 143 & 174 & 142 & 145 \\
\hline Glycosylated hemoglobin (\%) & $6.6 \%$ & $8.3 \%$ & $10.2 \%$ & $6.8 \%$ \\
\hline C-peptide (RV 0.8-4.2 ng/mL) & & & 0.91 & 2.45 \\
\hline $\begin{array}{l}\text { Antiglutamine acid decarboxylase } \\
\text { antibody (RV }<10 \mathrm{UI} / \mathrm{mL})\end{array}$ & & & Negative & \\
\hline Islet cell antibody (RV Non-reagent) & & & Negative & \\
\hline Anti-insulin antibody (RV < 8.2\%) & & & Negative & \\
\hline Total cholesterol (RV < 200 mg/dL) & 176 & 203 & 282 & 163 \\
\hline LDL (RV < 130 mg/dL) & 94 & 109 & 158 & 80 \\
\hline HDL (RV > 50 mg/dL) & 60 & 63 & 60 & 54 \\
\hline Triglycerides (RV < 150 mg/dL) & 109 & 159 & 323 & 143 \\
\hline $\begin{array}{l}\text { Aspartate aminotransferase } \\
(\mathrm{RV}<35 \mathrm{U} / \mathrm{L})\end{array}$ & 42 & 45 & 37 & 25 \\
\hline $\begin{array}{l}\text { Alanine aminotransferase } \\
(\mathrm{RV}<35 \mathrm{U} / \mathrm{L})\end{array}$ & 65 & 72 & 65 & 41 \\
\hline $\begin{array}{l}\text { Alkaline phosphatase } \\
\text { (RV 30-120 U/L) }\end{array}$ & 132 & 143 & 137 & 131 \\
\hline $\begin{array}{l}\text { Gamma-glutamyl transferase } \\
(9-64 \text { U/L) }\end{array}$ & 699 & 701 & 730 & 429 \\
\hline
\end{tabular}

autosomal dominant, recessive and $\mathrm{X}$-linked recessive inheritance. Recently, human genetics studies have also revealed some genes that are responsible for leftright laterality and $\mathrm{HS}$, such as ZIC3, NODAL, and LEFTY2 $(11,12)$.

Heterotaxy with polysplenia, as in our case, is the most common type of HS and has an increased frequency in women. Commonly, it is characterized by multiple spleens associated with a pattern of abnormalities in several other systems $(13,14)$. However, these patients may also have a single-lobed spleen or even a normal spleen. Affected patients have a low prevalence of congenital heart diseases and less severe defects than patients with HS and asplenia, but when cardiac lesions are associated with this syndrome, the 1-year mortality rate can rise up to $50 \%$ (15-17).

The exact prevalence of pancreatic disorders related to HS with polysplenia is not known, but in a series of eight cases, Gayer and cols. (18) reported that four patients had a short pancreas. Dorsal pancreatic agenesis is usually an asymptomatic condition and may be found incidentally, during the investigation of other diseases. However, patients may complain of abdominal pain and present hyperglycemia. Hyperglycemia is seen in approximately $50 \%$ of cases, owing to loss of islet cells that are mainly found in the tail and body of the pancreas $(19,20)$.

Jung and cols. (8) described the first case of DM due to agenesis of dorsal pancreas in a 13-year-old girl with HS and several cardiac and extracardiac disorders. Our patient, differently from the first case report, has HS with polysplenia and agenesis of the dorsal pancreas, but we did not find any cardiac abnormality. She developed DM at 36 years of age and had a transitory worsening in glycemic control four years after the diagnosis, in association with clinical signs of insulin resistance (acanthosis nigricans and increased waist circumference) and weight gain.

Initially, the patient presented a low C-peptide level and required high doses of insulin, but after an improvement in glycemic control, we were able to restart oral medications (metformin and sitagliptin) and decrease insulin doses. The evaluation of clinical characteristics, especially the signs of insulin resistance and the level of peptide $\mathrm{C}$, was important to guide the decision to restart oral medications in an attempt to improve glycemic sensitivity in a patient with altered pancreatic anatomy.

It is quite difficult to affirm the etiology for the worsening in glycemic control observed in this patient. It could be due to a natural evolution of the disease or, more likely, to the progressive weight gain and consequent insulin resistance being responsible for the worsening in glycemic control in a patient with a diminished pancreatic reserve due to the loss of islet cells that predominate in the body and tail of pancreas (21).

In conclusion, although HS with polysplenia and pancreatic disorder is a rare anomaly, it can be associated with an increased risk of pancreatitis and DM. While a case of HS with dorsal pancreas agenesis and DM was already described, we present a different type of HS coexisting with polysplenia, agenesis of dorsal pancreas and DM in a 40-year-old woman. This case highlights the importance of investigating DM in patients with HS, especially those with pancreatic anatomical disorders, for proper clinical management of this rare condition.

Acknowledgments and author contributions: CM Riguetto, $S$ Pelichek and A Moura Neto wrote this article and were the physicians involved in the care and follow-up of the patient. All au- 
thors read and approved the final manuscript. The authors thank the patient for giving the informed consent for this publication.

Funding: this research did not receive any specific grant from any funding agency.

Disclosure: no potential conflict of interest relevant to this article was reported.

\section{REFERENCES}

1. Peoples WM, Moller JH, Edwards JE. Polysplenia: a review of 146 cases. Pediatr Cardiol. 1983;4(2):129-37.

2. Williams GD, Feng A. Heterotaxy syndrome: implications for anesthesia management. J Cardiothorac Vasc Anesth. 2010;24(5):834-44.

3. Carneiro DS, Arantes JH, Souza GV, Barreto AS, Cardoso ML, Gontijo F. Síndrome de heterotaxia: relato de caso. Radiol Bras. 2013;46(3):181-3.

4. Kim SJ. Heterotaxy syndrome. Korean Circ J. 2011;41(5):227-32.

5. SchnedI WJ, Piswanger-Soelkner C, Wallner SJ, Reittner P, Krause R, Lipp RW, et al. Agenesis of the dorsal pancreas and associated diseases. Dig Dis Sci. 2009;54(3):481-7.

6. Kim SJ, Kim WH, Lim HG, Lee JY. Outcome of 200 patients after an extracardiac Fontan procedure. J Thorac Cardiovasc Surg. 2008;136(1):108-16.

7. Ito H, Ohgi S, Kanno T, Ishibashi T. Heterotaxy syndrome with pancreatic malrotation: CT features. Abdom Imaging. 2003;28(6):856-8.

8. Jung JE, Hur JH, Jung MK, Kwon A, Chae HW, Kim DH, et al. Diabetes mellitus due to agenesis of the dorsal pancreas in a patient with heterotaxy syndrome. Ann Pediatr Endocrinol Metab. 2017;22(2):125-8.

9. Applegate KE, Goske MJ, Pierce G, Murphy D. Situs revisited: imaging of the heterotaxy syndrome. Radiographics. 1999;19(4):83752; discussion 53-4.
10. Gayer G, Apter S, Jonas T, Amitai M, Zissin R, Sella T, et al. Polysplenia syndrome detected in adulthood: report of eight cases and review of the literature. Abdom Imaging. 1999;24(2):178-84.

11. Britz-Cunningham SH, Shah MM, Zuppan CW, Fletcher WH. Mutations of the Connexin43 gap-junction gene in patients with heart malformations and defects of laterality. $\mathrm{N}$ Engl J Med. 1995;332(20):1323-9.

12. Shiraishi I, Ichikawa H. Human heterotaxy syndrome - from molecular genetics to clinical features, management, and prognosis. Circ J. 2012;76(9):2066-75.

13. Lang K, Lasson A, Muller MF, Thorlacius H, Toth E, Olsson R. Dorsal agenesis of the pancreas - a rare cause of abdominal pain and insulin-dependent diabetes. Acta Radiol. 2012;53(1):2-4.

14. Liang K, Ou X, Huang X, Lan $Q$. Agenesis of the dorsal pancreas: a rare cause of insulin-dependent diabetes without abdominal pain: Case report. Medicine (Baltimore). 2018;97(9):e0046.

15. Mishra S. Cardiac and Non-Cardiac Abnormalities in Heterotaxy Syndrome. Indian J Pediatr. 2015;82(12):1135-46.

16. Shimodaira M, Kumagai $N$, Sorimachi E, Hara M, Honda K. Agenesis of the dorsal pancreas: a rare cause of diabetes. Intern Emerg Med. 2012;7(1):83-4.

17. Sonkar SK, Kumar S, Singh NK. Agenesis of dorsal pancreas in a young adult: a rare cause of diabetes mellitus. BMJ Case Rep. 2018;2018

18. Gayer G, Apter S, Jonas T, Amitai M, Zissin R, Sella T, et al. Polysplenia syndrome detected in adulthood: report of eight cases and review of the literature. Abdom Imaging. 1999;24(2):178-84.

19. Ticho BS, Goldstein AM, Van Praagh R. Extracardiac anomalies in the heterotaxy syndromes with focus on anomalies of midlineassociated structures. Am J Cardiol. 2000;85(6):729-34.

20. Thakur S, Jhobta A, Sharma D, Thakur CS. MR in complete dorsal pancreatic agenesis: Case report and review of literature. Indian J Radiol Imaging. 2014;24(2):156-9.

21. Wittingen J, Frey CF. Islet concentration in the head, body, tail and uncinate process of the pancreas. Ann Surg. 1974;179(4):412-4. 